eds. Handbook of clinical neurology vol 18. Amsterdam: North Holland Publishing Company, 1975: 73-9.

3 Wechsler LR, Gross RA, Miller DC. Meningeal gliomatosis with "negative" CSF cytology: the value of GFAP staining. Neurology 1984;34:1611-5.

4 Scheinker IM, Evans JP. Diffuse cerebral glioblastosis. $J$ Neuropathol Exp Neurol 1943;2:78-189.

5 Artigas J, Cervos-Navarro J, Iglesias JR, Ebhardt G. Gliomatosis cerebri: clinical and histological findings. Review article. Clin Neuropathol 1985;4:135-48.
6 Kawano N, Miyasaka Y, Yada K, Atari H, Sasaki K. Diffuse cerebrospinal gliomatosis: case report. $J$ Neurosurg 1978;49:303-7.

7 Ferraro A, Jervis GA, Sherwood WD. Patchy blastomatous infiltration of the central nervous system (patchy schwannosis?). J Neuropathol Exp Neurol 1943;2:207-25.

8 Moore MT. Diffuse cerebrospinal gliomatosis, masked by syphilis. J Neuropathol Exp Neurol 1954;13 129-43.

9 Nevin S. Gliomatosis cerebri. Brain 1938;61:170-91.

\title{
Bromide: from neurology to English
}

When a neurologist speaks of a "clinical bromide", the term is most fitting; indeed, the neurologist is entitled to use it in ano $\mathrm{N}$ almost proprietary manner. The derogatory sense of the word came into usage years after bromides were first given in the $\infty$

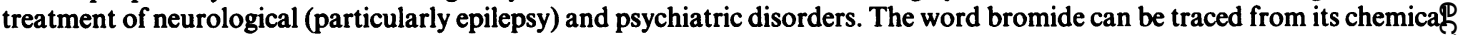
origin to its second meaning in literate English usage via neurology.

Bromine was discovered in 1826 by a French chemist, Antoine Balard, and was subsequently named such after the Gree bromos ("stink"). It seems that Balard called it muride, a name which was later changed to bromine by the Academie Francaise;' however, the naming of bromine is attributed to Balard elsewhere. ${ }^{2}$

Though others may have been instrumental in propagating the use of bromides for epilepsy, ${ }^{3}$ Sir Charles Locock has bee given priority. He commented on his success with potassium bromide at a meeting in 1857, after Sieveking had spoken on the current state of therapeutics. ${ }^{4}$ Locock was not a neurologist, but an obstetrician, and accoucheur to the high-born, including Queen Victoria. Locock had apparently read a case report of impotence following potassium bromide ingestion. His Victorian notions on the origins of epilepsy (as stemming from onanism in some cases) led him to try the bromide as an antiaphrodisiac, and therefore antiepileptic, drug; he had first used it with good results in women with hysteria, and later, hysterical epilepsy. ${ }^{56}$ It became the mainstay in the treatment of seizures until well into this century, and was widely used as a sedative as well.

Priority for the use of bromide in the nonelemental sense is open to question. According to the Dictionary of American Slang, Gelett Burgess coined the slang (for that time, if not now) meaning, with his 1906 book, Are You a Bromide?' Another source gives this account: "Bromo-seltzer being used as a sedative, the magazine Smart Set, in April, 1906, suggested the word bromide for persons and expressions that tend to put one to sleep." ${ }^{8}$ In any event, it is fortunate for epileptics that the English usage is now more common than the neurological.

Other word meanings have been introduced into English via neurologic disorders. Most are generally regarded as slang, including "had a fit", "hysterical", and perhaps the youthful usages of "hyper" and "spastic". "Knee jerk" is another of these slang terms, used mainly as a modifier before the contrary of one's politics. The term in the neurological sense was first used by W R Gowers in 1879; the reflex had been described under other names before. ${ }^{9}$

K G WOODWARD, MD, The Hammond Clinic, 7905 Calumet, Munster, IN, USA 46321.

\section{References}

1 Academic American Encyclopedia. Danbury, CN: Grolier Inc., 1985:502.

2 Klein E. A Comprehensive Etymological Dictionary of the English Language. Amsterdam: Elsevier, 1966:202.

3 Friedlander WJ. Who was "the father of bromide treatment of epilepsy"? Arch Neurol 1986;43:505-7.

4 Locock C, in discussion, Sieveking EH. Analysis of 52 cases of epilepsy observed by the author. Lancet 1857;i:527-8.

5 Joynt RJ. The use of bromides for epilepsy. AJDC 1974;128:362-3.

6 Lennox WG. The centenary of bromides. $N$ Engl J Med 1957;256:887-90.

7 Wentworth H, Flexner SB, eds. Dictionary of American Slang, Second Supplemental Edition. New York: Thomas Y. Crowell Co., 1975:64.

8 Shipley JT. Dictionary of Word Origins, 2nd ed. New York: Greenwood Press, 1945:58.

9 Tyler KL, McHenry LC. Fragments of neurological history[:] The knee jerk and other tendon reflexes. Neurology 1983;33:609-10. 